\title{
Direct Cardiac and Peripheral Vascular Effects of Intracoronary and Intravenous Nifedipine
}

\author{
SUSAN TERRIS, MD, PhD, PATRICK D. BOURDILLON MD, DAVID T. CHENG, MD, \\ and BERTRAM PITT, MD
}

The hemodynamic effects of a new parenteral formulation of nifedipine administered by the intravenous (1 mg) and intracoronary (IC) (0.1 and 0.2 $\mathrm{mg}$ ) routes were studied in 10 patients with symptomatic coronary artery disease undergoing diagnostic right- and left-sided cardiac catheterization. Intravenous nifedipine $(1 \mathrm{mg})$ reduced systemic vascular resistance by $34 \%(p<0.01)$, increased cardiac output by $28 \%(p<0.01)$ and decreased mean arterial pressure by $10 \%$ (p <0.01). It had less effect on peak positive $\mathrm{dP} / \mathrm{dt}(-8 \% \mathrm{p}$ $<0.025)$ and on peak negative $\mathrm{dP} / \mathrm{dt}(-15 \% \mathrm{p}$ $<0.01$ ). Coronary blood flow increased $20 \%$ (p $<0.025)$. In contrast, IC nifedipine $(0.2 \mathrm{mg})$ increased coronary blood flow $46 \%(p<0.025)$, depressed contractility as assessed by peak positive $\mathrm{dP} / \mathrm{dt}(-26 \%$ p $<0.01)$ and prolonged dlastollc relaxation time. The effect of $0.1 \mathrm{mg}$ was similar but less pronounced. These data suggest that the primary therapeutic effect of nifedipine administered systemically to patients at rest results from an increase in coronary blood flow and, to a lesser extent, from afterload reduction; its myocardial depressant effects are small, transient and masked by reflex catecholamine release. IC nifedipine increases coronary blood flow, has a transient negative inotropic effect and prolongs relaxation. The relative importance of these myocardial effects in preventing myocardial ischemia is not known.

(Am J Cardiol 1986;58:25-30)
N ifedipine, a calcium-channel blocking drug, has negative inotropic and vasodilatory effects in vitro, but acts primarily as a vasodilator in vivo. ${ }^{1,2}$ It is effective in the treatment of angina pectoris due to coronary vasospasm $^{3-5}$ or after exertion..$^{6-8}$ Administered systemically, its efficacy in ameliorating pacing- and exercise-induced angina has been attributed to afterload reduction, ${ }^{6,7,9,10}$ to increased coronary blood flow ${ }^{9,11}-$ via a direct vasodilatory effect or by reducing extrinsic coronary vascular compressive forces in diastole $e^{8,10}$ and to a direct myocardial effect. ${ }^{12}$ Administered by the intracoronary (IC) route, nifedipine increases coronary sinus flow, ${ }^{11-13}$ decreases myocardial oxygen consumption, ${ }^{13,14}$ relieves spontaneous or ergonovine-induced coronary artery spasm ${ }^{4}$ and prolongs regional shortening, ${ }^{15}$ thereby prolonging relaxation time. ${ }^{16}$ Kaltenbach et $\mathrm{al}^{12}$ observed that the antianginal effect

From the Division of Cardiology, Department of Internal Medicine, University of Michigan Medical Center, Ann Arbor, Michigan. Manuscript received October 14, 1985; revised manuscript received January 23, 1986, accepted January 24, 1986.

Address for reprints: Patrick D. Bourdillon, MD, Cardiology Division, University Hospital, 1405 East Ann Street, Ann Arbor Michigan 48109. of IC nifedipine persisted for 10 minutes longer than its effect on hemodynamics and on coronary flow and, on that basis, suggested that intracoronary nifedipine has a direct myocardial effect. This study relates the direct myocardial effects of the drug administered by the IC route to changes in coronary blood flow in patients with ischemic disease, and compares these effects with those of nifedipine administered by the intravenous (IV) route.

\section{Methods}

Patients: Ten patients ( 8 men, 2 women), 38 to 59 years old, who underwent diagnostic cardiac catheterization for symptomatic coronary artery disease were studied (Table I). Mean ejection fraction was $63 \%$. None had valvular or congenital heart disease, unstable angina, second- or third-degree heart block, major systemic disorders or diabetes mellitus.

Protocol: Topical nitrate and $\beta$-blocker therapy were stopped 48 hours, and calcium-channel blocker therapy 72 hours before catheterization. After routine right- and left-sided cardiac catheterization and coronary arteriography, the baseline hemodynamic values were measured. They included heart rate, blood pressure, left ventricular pressure (4Fr or $5 \mathrm{Fr}$ Millar micro- 
TABLE I Clinical Characteristics

\begin{tabular}{|c|c|c|c|c|c|c|c|}
\hline \multirow[b]{2}{*}{ Pt } & \multirow{2}{*}{$\begin{array}{c}\text { Age (yr) } \\
\& \text { Sex }\end{array}$} & \multirow{2}{*}{$\begin{array}{l}\text { EF } \\
(\%)\end{array}$} & \multirow{2}{*}{$\begin{array}{c}L V \\
(\mathrm{~s} / \mathrm{d}) \\
(\mathrm{mm} \mathrm{Hg})\end{array}$} & \multicolumn{4}{|c|}{ \% Diameter Stenosis at CA } \\
\hline & & & & LM & LAD & LC & $\mathbf{R}$ \\
\hline 1 & $38 \mathrm{M}$ & 71 & $126 / 20$ & $\ldots$ & $\ldots$ & 60 & $\cdots$ \\
\hline 2 & 63F & 63 & $146 / 11$ & $\cdots$ & $\ldots$ & 70 & $\ldots$ \\
\hline 3 & $63 M$ & 50 & $134 / 12$ & 50 & $\ldots$ & $\ldots$ & $\ldots$ \\
\hline 4 & $59 \mathrm{M}$ & 54 & $140 / 6$ & $\ldots$ & 40 & $\ldots$ & $\ldots$ \\
\hline 5 & $55 \mathrm{M}$ & 78 & $114 / 9$ & $\ldots$ & 60 & $\ldots$ & $\ldots$ \\
\hline 6 & $49 M$ & 76 & $115 / 8$ & $\cdots$ & 90 & 70 & $\ldots$ \\
\hline 7 & $46 \mathrm{M}$ & 67 & $103 / 14$ & .. & $\therefore$ & 90 & $\ldots$ \\
\hline 8 & $50 \mathrm{M}$ & 55 & $106 / 6$ & $\ldots$ & 70 & $\ldots$ & 80 \\
\hline 9 & $50 \mathrm{M}$ & 45 & $124 / 11$ & $\ldots$ & 90 & $\ldots$ & 90 \\
\hline 10 & $57 \mathrm{M}$ & 68 & $107 / 12$ & $\ldots$ & 50 & $\ldots$ & 90 \\
\hline
\end{tabular}

$\mathrm{CA}=$ coronary arteriography; $\mathrm{EF}=$ ejection fraction; $\mathrm{LAD}=$ left anterio descending artery; $L C=$ left circumflex artery; $L M=$ left main artery; $L V$ (s/d) $=$ left ventricular systolic/end-diastolic pressure; $\mathbf{R}=$ right coronary artery.

manometer-tip catheter), electronically differentiated left ventricular $\mathrm{dP} / \mathrm{dt}$, pulmonary capillary wedge, pulmonary artery and right atrial pressures, cardiac output (thermodilution, Swan-Ganz catheter) and coronary sinus flow (thermodilution, Wilton-Webster catheter through the left antecubital vein). Measurement of coronary blood flow remained stable: coronary flows measured before infusion of different doses were the same, and coronary flows at the end of a period of observation were the same as at the beginning (Tables II, III and IV). After 2 successive measurements were stable, nifedipine $(0.1 \mathrm{mg} / 10 \mathrm{ml}$ of vehicle) was infused over 30 seconds with an infusion pump (Harvard model 2803) into the left coronary artery. Pressures, cardiac output and coronary sinus flow were measured at baseline, after the infusion was stopped (time 0 ) and at $1,3,5$ and 10 minutes. After restabilization of measurements, $0.2 \mathrm{mg} / 10 \mathrm{ml}$ of vehicle was infused over 60 seconds and measurements were repeated. Then, $1 \mathrm{mg}$ was infused by the IV route over 3 minutes; measurements were made at the end of infusion, at 1, 3, 5 minutes and every 5 minutes thereafter for 30 minutes.

Evaluation of data: All phasic pressures were determined as the mean of 5 successive sinus beats over 1 respiratory cycle. Cardiac outputs represent the mean of 3 measurements. The value of a hemodynamic parameter was calculated as the absolute or percent difference between the baseline value and each subsequent value. The time constant of relaxation, $\tau$, was derived from the best fit of a monoexponential to the time course of isovolumic left ventricular pressure decay. ${ }^{17,18}$ The correlation coefficients for these experimental fits were never less than 0.97 . Statistical significance was determined using a Student $t$ test on paired differences between the valuc of a homodynamic variable at any time during the infusion and its baseline value.

\section{Results}

Systemic effects of nifedipine (Tables II, III and IV, Fig. 1 and 2): After IV administration, left ventricular systolic pressure decreased by $22 \pm 12 \mathrm{~mm} \mathrm{Hg}$ (p $<0.01$ ), mean arterial pressure by $10 \pm 6 \mathrm{~mm} \mathrm{Hg}$ (p $<0.01$ ) and systemic vascular resistance by $422 \pm 228$ dynes $\mathrm{s} \mathrm{cm}^{-5}(\mathrm{p}<0.01)$. These effects lasted for only 5 to 10 minutes. Heart rate increased transiently and cardiac index rose by $0.8 \pm 0.6$ liters $/ \mathrm{min} / \mathrm{m}^{2}(\mathrm{p}<0.01)$. As assessed by systolic pressure-rate product, external cardiac work was reduced for at least 15 minutes after drug administration. Left ventricular end-diastolic pressure, peak positive and negative $\mathrm{dP} / \mathrm{dt}$ and $\tau$ changed little. In contrast, the systemic effects of IC nifedipine were small and short-lived.

Direct effects of nifedipine (Tables II, III and IV, Fig. 1 and 2): Cardiac: IC nifedipine (0.1 mg) depressed

TABLE II Hemodynamic Effects of Intracoronary Nifediplne (0.1 mg)

\begin{tabular}{|c|c|c|c|c|c|c|}
\hline & \multirow[b]{2}{*}{ Baseline } & \multicolumn{5}{|c|}{ Time (minutes) } \\
\hline & & 0 & 1 & 3 & 5 & 10 \\
\hline PCW (mm Hg) & $7 \pm 2(9)$ & $+7 \pm 1(2)^{\ddagger}$ & $+0.8 \pm 2.5(6)$ & $+0.9 \pm 2.2(7)$ & $+1.0 \pm 2.0(8)$ & $+2.4 \pm 2.2(8)^{\dagger}$ \\
\hline LVEDP $(\mathrm{mm} \mathrm{Hg})$ & $10 \pm 5$ & $+2 \pm 6$ & $+1 \pm 5$ & $0 \pm 4(9)$ & $+1 \pm 3$ & $+1.4 \pm 4$ \\
\hline +dP/dt $(\mathrm{mm} \mathrm{Hg} / \mathrm{s})$ & $1,067 \pm 171$ & $-223 \pm 118^{*}$ & $-110 \pm 113^{t}$ & $-4 \pm 73$ & $-4 \pm 73$ & \\
\hline -dP/dt (mm Hg/s) & $1,231 \pm 203$ & $-360 \pm 216^{*}$ & $-221 \pm 83^{*}$ & $-88 \pm 113(9)$ & $-72 \pm 126$ & $-55 \pm 86$ \\
\hline$\tau\left(s^{-1}\right)$ & $45.0 \pm 6.9$ & $+6.2 \pm 32$ & $+4.2 \pm 20.0$ & $+0.6 \pm 14.5$ & - & $+0.5 \pm 9.6$ \\
\hline $\mathrm{CBF}(\mathrm{ml} / \mathrm{min})$ & $162 \pm 27(6)$ & & $+62 \pm 49(6)^{\ddagger}$ & $+16 \pm 22(2)$ & $+4 \pm 8(6)$ & $+2 \pm 26(6)$ \\
\hline $\begin{array}{l}\text { CVR } \\
\qquad(\mathrm{mm} \mathrm{Hg} / \mathrm{ml} / \mathrm{min})\end{array}$ & $0.56 \pm 0.14(6)$ & & $-0.18 \pm 0.15(5)$ & $+0.08 \pm 0.11(6)$ & $+0.03 \pm 0.19(5)$ & $-0.01 \pm 0.15(5)$ \\
\hline HR (beats/min) & $73 \pm 10$ & $+7 \pm 7^{*}$ & $+4 \pm 6$ & $0 \pm 6(9)$ & $0 \pm 6$ & $+2 \pm 7$ \\
\hline $\operatorname{MAP}(\mathrm{mm} \mathrm{Hg})$ & $94 \pm 11$ & $-11 \pm 4(5)$ & $-6 \pm 7(7)$ & $-1 \pm 7(7)$ & $-4 \pm 7(8)$ & $0 \pm 14(9)$ \\
\hline LVSP (mm Hg) & $122 \pm 15$ & $-16 \pm 12^{*}$ & $-8 \pm 13$ & $-4 \pm 6(9)$ & $+4 \pm 6^{\ddagger}$ & $+3 \pm 12$ \\
\hline CO (liters/min) & $5.6 \pm 0.7$ & & $+0.4 \pm 0.4(6)$ & $+0.4 \pm 0.4(7)^{*}$ & $0.2 \pm 0.3(9)$ & $0.3 \pm 0.5$ \\
\hline $\mathrm{Cl}$ (liters $/ \mathrm{min} / \mathrm{m}^{2}$ ) & $2.8 \pm 0.3$ & & $0.2 \pm 0.2(6)$ & $+0.3 \pm 0.2(7)^{*}$ & $-0.1 \pm 0.1(9)^{\dagger}$ & $+0.2 \pm 0.2^{\dagger}$ \\
\hline SVR (dynes s $\mathrm{cm}^{-5}$ ) & $1,296 \pm 236$ & & $-201 \pm 253(5)$ & $-106 \pm 116(6)$ & $-33 \pm 124(9)$ & $-93 \pm 22 t$ \\
\hline DP ( $\%$ of baseline) & 100 & & $99 \pm 10$ & & $100 \pm 10$ & $110 \pm 15$ \\
\hline
\end{tabular}

Data are expressed as the mean change from baseline \pm standard deviation. The number of patients evaluated is in parentheses unless the number is 10 . " $p<0.01 ;{ }^{\dagger} p<0.025 ;{ }^{\ddagger} p<0.05$ by paired $t$ test.

$\mathrm{CBF}=$ coronary blood flow; $\mathrm{Cl}=$ cardiac index; $\mathrm{CO}=$ cardiac output; $\mathrm{CVA}=$ coronary vascular resistance; $\mathrm{DP}=\mathrm{double}$ product; $+\mathrm{dP} / \mathrm{dt}=\mathrm{peak}$ positive $\mathrm{dP} / \mathrm{dt} ;-\mathrm{dP} / \mathrm{dt}=$ peak negative $\mathrm{dP} / \mathrm{dt} ; \mathrm{LVEDP}=$ left ventricular end-diastolic pressure; LVSP = left ventricular systolic pressure; $\mathrm{MAP}=$ mean arterial pressure; PCW = pulmonary capillary wedge pressure; SVR = systemic vascular resistance; $\tau=$ time constant of relaxation. 
TABLE III Hemodynamic Effects of Intracoronary Nifedipine (0.2 mg)

\begin{tabular}{lcccccc}
\hline & & \multicolumn{5}{c}{ Time (minutes) } \\
\cline { 3 - 6 } & Baseline & 0 & 1 & 3 & 5 & 10 \\
\hline PCW & $8 \pm 3$ & $+3 \pm 3(6)$ & $-2 \pm 6(9)$ & $0 \pm 3$ & $0 \pm 2$ & $0 \pm 2(8)$ \\
LVEDP & $11 \pm 3$ & $+6 \pm 4^{*}$ & $+3 \pm 3^{\ddagger}$ & $+1 \pm 4(9)$ & $+1 \pm 2$ & $-2 \pm 2(8)^{\dagger}$ \\
tdP/dt & $1,068 \pm 169$ & $-273 \pm 116^{*}$ & $-174 \pm 93^{*}$ & $-25 \pm 85(9)$ & $-2 \pm 48(10)$ & $-16 \pm 90(8)$ \\
-dP/dt & $1,169 \pm 164$ & $-327 \pm 173^{*}$ & $-176 \pm 142^{*}$ & $-113 \pm 292(9)$ & $-7 \pm 65(9)$ & $+32 \pm 87(8)$ \\
$\tau$ & $48.6 \pm 9.3$ & $+13.1 \pm 8.0^{*}$ & $+7.1 \pm 10.8(8)$ & $-5.7 \pm 9.4(7)$ & $-5.7 \pm 9.4(7)$ & $+0.2 \pm 7.9$ \\
CBF & $172 \pm 30(6)$ & & $+79 \pm 71(6)^{\ddagger}$ & $+1 \pm 10(4)$ & $-9 \pm 37(6)$ & $-2 \pm 31(6)$ \\
CVR & $0.51 \pm 0.12(6)$ & & $-0.16 \pm 0.12(6)^{\dagger}$ & $-0.09 \pm 0.07(4)$ & $+0.08 \pm 0.14(6)$ & $+0.05 \pm 0.11(6)$ \\
HR & $71 \pm 8$ & $+11 \pm 8^{*}$ & $+8 \pm 11$ & $+2 \pm 7$ & $-1 \pm 6$ & $+1 \pm 7$ \\
MAP & $92 \pm 9$ & $-6 \pm 3(5)$ & $-5 \pm 11(9)$ & $+1 \pm 12$ & $+6 \pm 13$ & $+4 \pm 15(8)$ \\
LVSP & $123 \pm 14$ & $-19 \pm 7^{*}$ & $-12 \pm 12^{\dagger}$ & $-2 \pm 7$ & $-1 \pm 8$ & $+1 \pm 10(8)$ \\
CO & $5.8 \pm 0.5$ & & $+0.7 \pm 0.8(8)^{\ddagger}$ & $+0.5 \pm 1.0(4)$ & $0.0 \pm 0.7$ & $+0.1 \pm 0.7(8)$ \\
Cl & $2.9 \pm 0.3$ & & $0.2 \pm 0.4$ & $+0.2 \pm 0.4(4)$ & $+0.0 \pm 0.5$ & $+0.0 \pm 0.4$ \\
SVR & $1,197 \pm 169$ & & $-130 \pm 165(9)^{\ddagger}$ & $-91 \pm 166(4)$ & $+110 \pm 190$ & $+48 \pm 159$ \\
DP & 100 & & & & $102 \pm 0$ & $103 \pm 17$ \\
\hline
\end{tabular}

Data are expressed as the mean change from baseline \pm standard deviation. The number of patients evaluated is in parentheses unless the number is 10 . ${ }^{*} \mathrm{p}<0.01 ;{ }^{\dagger} \mathrm{p}<0.025 ;{ }^{\ddagger} \mathrm{p}<0.05$ by paired $t$ test.

Abbreviations as in Table I.

peak positive $\mathrm{dP} / \mathrm{dt}$ by $223 \pm 118 \mathrm{~mm} \mathrm{Hg} / \mathrm{s}$ (p <0.01) and $0.2 \mathrm{mg}$ of nifedipine by $273 \pm 116 \mathrm{~mm} \mathrm{Hg} / \mathrm{s}$ (p $<0.01$ ), significantly more than did IV nifedipine ( $87 \pm$ $90 \mathrm{~mm} \mathrm{Hg} / \mathrm{s} \mathrm{p} \mathrm{<0.025).} \mathrm{These} \mathrm{effects} \mathrm{were} \mathrm{transient.}$ Nifedipine (0.2 mg IC) significantly depressed early diastolic relaxation: $\tau$ was prolonged by $30 \%(\mathrm{p}<0.01)$. It also reduced compliance, as reflected by the increase in left ventricular end-diastolic pressure. Although IV nifedipine significantly reduced peak negative $\mathrm{dP} / \mathrm{dt}$, the effect was not significant, since $\tau$ was unaffected.

Coronary vascular: Both IV and IC nifedipine reduced coronary vascular resistance by 30 to $40 \%$. IC nifedipine, $0.1 \mathrm{mg}$, increased coronary blood flow by $39 \pm 17 \%$ ( $\mathrm{p}<0.05)$, and $0.2 \mathrm{mg}$ by $46 \pm 17 \%$ ( $\mathrm{p}<0.05$ ) without altering myocardial oxygen consumption as assessed by the systolic pressure-rate product. IV ni- fedipine increased coronary blood flow by only $20 \%$; nonetheless, this occurred without a significant reduction in systolic pressurc-rate product.

\section{Discussion}

Our data suggest that the antianginal effect of IV nifedipine results more from an increase in myocardial oxygen supply than from a reduction in myocardial oxygen consumption or in myocardial contractility. Despite the marked decrease in systemic vascular resistance, the reduction of mean arterial pressure was small. Reflex tachycardia, reflecting catecholamine release, precluded a marked and sustained reduction of systolic pressure-rate product, an adequate index of myocardial oxygen consumption that takes catecholamine effects into account. ${ }^{19} \mathrm{Koch}^{20}$ observed higher catecholamine levels among patients undergoing su-

TABLE IV Hemodynamic Effects of Intravenous Nifedipine $(1.0 \mathrm{mg})$

\begin{tabular}{|c|c|c|c|c|c|c|c|}
\hline & \multirow[b]{2}{*}{ Baseline } & \multicolumn{6}{|c|}{ Time (minutes) } \\
\hline & & 0 & 1 & 3 & 5 & 10 & 30 \\
\hline PCW & $8 \pm 2$ & $1 \pm 2(8)$ & $+1 \pm 2(6)$ & $+1.3 \pm 2.4(8)$ & $+1 \pm 2$ & $0 \pm 2$ & $0 \pm 2$ \\
\hline LVEDP & $12 \pm 4$ & $+1 \pm 4$ & $0 \pm 3$ & $+1 \pm 3$ & $+1 \pm 3$ & $+1 \pm 4$ & $0 \pm 3(9)$ \\
\hline$+\mathrm{dP} / \mathrm{dt}$ & $1,081 \pm 203$ & $-87 \pm 90^{\dagger}$ & $-53 \pm 105$ & $+29 \pm 55$ & $+18 \pm 97$ & $-20 \pm 89$ & $+11 \pm 135$ \\
\hline$-\mathrm{dP} / \mathrm{dt}$ & $1,192 \pm 151$ & $-172 \pm 131^{*}$ & $-102 \pm 199$ & $-54 \pm 123$ & $-76 \pm 86^{\dagger}$ & $-52 \pm 79$ & $-7 \pm 133(9)$ \\
\hline$\tau$ & $48.3 \pm 10.8$ & $+5.8 \pm 11.1$ & $+2.1 \pm 9.8(9)$ & $+4.1 \pm 9.4(9)$ & $+4.1 \pm 9.4(9)$ & $+1.3 \pm 9.2$ & $-4.3 \pm 10.8$ \\
\hline $\mathrm{CBF}$ & $162 \pm 43(6)$ & & $+34 \pm 26(6)^{\dagger}$ & $+23 \pm 23(5)$ & $+27 \pm 55(6)$ & $+12 \pm 19(6)$ & $+22 \pm 47(6)$ \\
\hline CVR & $0.55 \pm 0.11(6)$ & & $-0.17 \pm 0.05(5)^{*}$ & $-0.09 \pm 0.07(5)^{\ddagger}$ & $-0.02 \pm 0.15(6)$ & $-0.05 \pm 0.07(6)$ & $-0.05 \pm 0.08(6)$ \\
\hline $\mathrm{HR}$ & $74 \pm 9$ & $+13 \pm 12^{*}$ & $+10 \pm 7^{\dagger}$ & $+6 \pm 8$ & $+2 \pm 8$ & $+1 \pm 6$ & $-1 \pm 8$ \\
\hline MAP & $94 \pm 7$ & $-10 \pm 6(9)^{*}$ & $-13 \pm 5(8)^{*}$ & $-8 \pm 6$ & $-4 \pm 7$ & $-4 \pm 4$ & $0 \pm 6$ \\
\hline LVSP & $123 \pm 17$ & $-22 \pm 12^{*}$ & $-21 \pm 12^{*}$ & $-14 \pm 13^{*}$ & $-11 \pm 13^{*}$ & $-11 \pm 9^{*}$ & $+1 \pm 13$ \\
\hline co & $5.9 \pm 0.9$ & & $+1.7 \pm 1.1(9)^{*}$ & $+1.2 \pm 0.6(9)^{*}$ & $+0.4 \pm 1.0(8)^{*}$ & $0.4 \pm 0.6$ & $-0.2 \pm 1.0$ \\
\hline $\mathrm{Cl}$ & $3.0 \pm 0.5$ & & $+0.8 \pm 0.6^{*}$ & $0.6 \pm 0.3(9)^{*}$ & $0.5 \pm 0.5(9)^{*}$ & $+0.2 \pm 0.3$ & $-0.1 \pm 0.4$ \\
\hline SVR & $1,238 \pm 262$ & & $-422 \pm 228(8)^{*}$ & $-327 \pm 161(8)^{*}$ & $-270 \pm 229(9)^{*}$ & $-49 \pm 400$ & $-12 \pm 188$ \\
\hline DP & 100 & $95 \pm 8.8$ & $94 \pm 7$ & & $94 \pm 10$ & $92 \pm 9$ & $103 \pm 14.6$ \\
\hline
\end{tabular}

Data are expressed as the mean change from baseline \pm standard deviation. The number of patients evaluated is in parentheses unless the number is 10 . ${ }^{*} p<0.01 ;{ }^{\top} p<0.025 ;{ }^{\top} p<0.05$ by paired $t$ test.

Abbreviations as in Table 1. 
pine bicycle exercise after administration of nifedipine than among control subjects.

Our data are in agreement with those of Schanzenbacher et al, ${ }^{13}$ who administered IV nifedipine to patients at rest, and with those of Specchia et al, ${ }^{11}$ who reported that the antianginal potency of nifedipine administered systemically to patients with exercise-induced angina was attributable almost entirely to an increase in coronary blood flow. However, our data are at variance with other reports. Engel,,$^{9}$ Emanuelsson $^{10}$ and their co-workers attributed the efficacy of nifedipine administered systemically to patients with pacing-induced angina both to afterload reduction and to increased myocardial perfusion. Moskowitz et $\mathrm{al}^{6}$ found that systemic nifedipine ameliorated exerciseinduced angina by reducing the double product at a given workload; however, myocardial oxygen supply was not measured. Kaltenbach et a ${ }^{12}$ reported that IV nifedipine reduced afterload and increased coronary
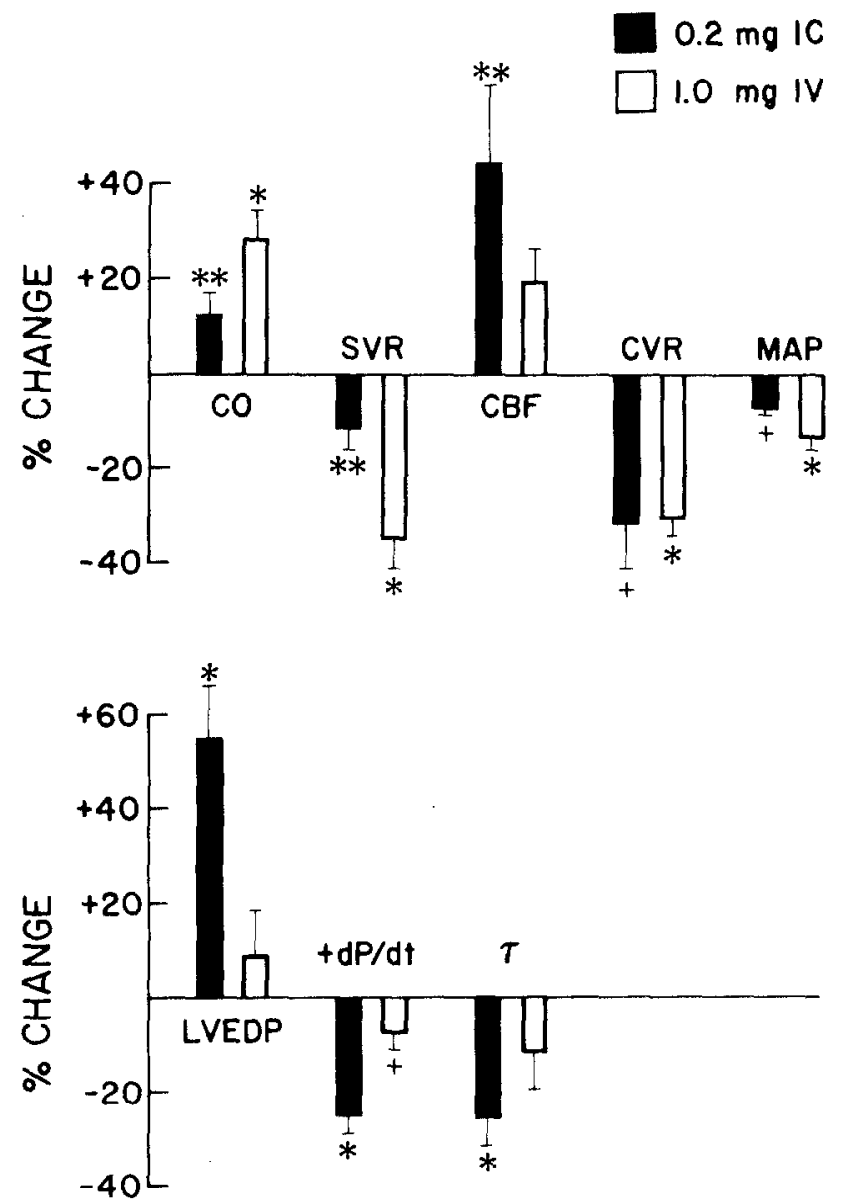

FIGURE 1. Peak hemodynamic effects of nifedipine infused by the intracoronary (IC) $(0.2 \mathrm{mg})$ and intravenous (IV) $(1.0 \mathrm{mg})$ routes. The difference between the baseline value and the peak value was calculated as a percentage of baseline value. The mean \pm standard error of the mean of the peak percentage change in all 10 patients is shown. ${ }^{*} p<0.01$; tp $<0.025$; * $p<0.05$ by paired $t$ test. CBF $=$ coronary blood flow; $\mathrm{CO}=$ cardiac output; $\mathrm{CVR}=$ coronary vascular resistance; $+\mathrm{dP} / \mathrm{dt}=$ peak positive $\mathrm{dP} / \mathrm{dt}$; $\mathrm{LVEDP}=$ lett ventricular end-diastolic pressure; MAP = mean arterlal pressure; SVR = systemic vascular resistance; $\tau=$ time constant of relaxation. blood flow, but also invoked a "direct myocardial influence" to explain the drug's antianginal effect. These differences may be explained by different doses and routes of drug administration, by the different levels of activity of the subjects or by different degrees of myocardial dysfunction.

The direct myocardial and coronary vascular effects of IC nifedipine help to rationalize the drug's transient antianginal effect. IC nifedipine depressed contractility, as evidenced by the decrease in peak positive $\mathrm{dP} / \mathrm{dt}$, which occurred despite an increase in heart rate; this was not attributable to the decrease in mean arterial pressure, since a larger and more sustained decrease in arterial pressure after IV nifedipine was not accompanied by a reduction of peak positive $\mathrm{dP} / \mathrm{dt}$ of a similar magnitude or duration. ${ }^{21}$ This observation is compatible with that of Serruys et al, ${ }^{15}$ who noted prolongation of systolic shortening in the distribution of vcin grafts after injection of nifedipine. Relaxation was prolonged, as observed by Serruys, ${ }^{22}$ Rousseau ${ }^{16}$ and their co-workers, probably because of drug-induced asynchronous myocardial contraction ${ }^{16}$ or to a direct myocardial effect on relaxation. Coronary blood flow was markedly increased in the absence of a significant change in double product. Although these effects explain a short-term antianginal effect observed by others, ${ }^{13,15}$ they do not explain the prolonged antianginal efficacy of IC nifedipine in exercise-induced ischemia reported by Kaltenbach et al. ${ }^{12}$ It is possible that autoregulatory mechanisms governing coronary blood flow mobilized by pacing- or exercise-induced ischemia may potentiate the effects of nifedipine, or that a direct biochemical effect of the drug not studied explicitly may persist for up to 15 minutes.

Nifedipine has been reported to normalize relaxation $^{8}$ when it is prolonged by ischemia ${ }^{23-27}$; under nonischemic conditions, it prolongs relaxation. ${ }^{16,22}$ IC nifedipine reduced peak negative $\mathrm{dP} / \mathrm{dt}$, although the effect may have been partially antagonized by catecholamine release. ${ }^{28,29}$ At the higher dose, $\tau$ was significantly prolonged; at the lower dose, the reduction of peak negative $\mathrm{dP} / \mathrm{dt}$ was attributable to a fall in left ventricular peak systolic pressure. ${ }^{17,18}$ Prolongation of diastole may reflect drug-induced slowing of calcium release in the perfused region, asynchronous contraction and subsequent prolonged relaxation. ${ }^{16,22}$ Under the nonischemic and eucalcemic conditions of this study, it is less likely that nifedipine improves relaxation by preventing intracellular calcium overload during systole, as suggested by recent studies of the effect of verapamil on chick embryo ventricular cells..$^{30}$

The present study confirms that the use of a parenteral formulation of nifedipine is safe, that IC nifedipine may be useful in the treatment of coronary spasm and that IV nifedipine may be useful in the treatment of hypertensive crises. In addition, the ability of IV nifedipine to lower systemic vascular resistance and increase cardiac output without depressing contractility suggests that it may be useful in the treatment of cardiac failure, particularly cardiac failure due to coronary artery disease. 
SYSTEMIC EFFECTS
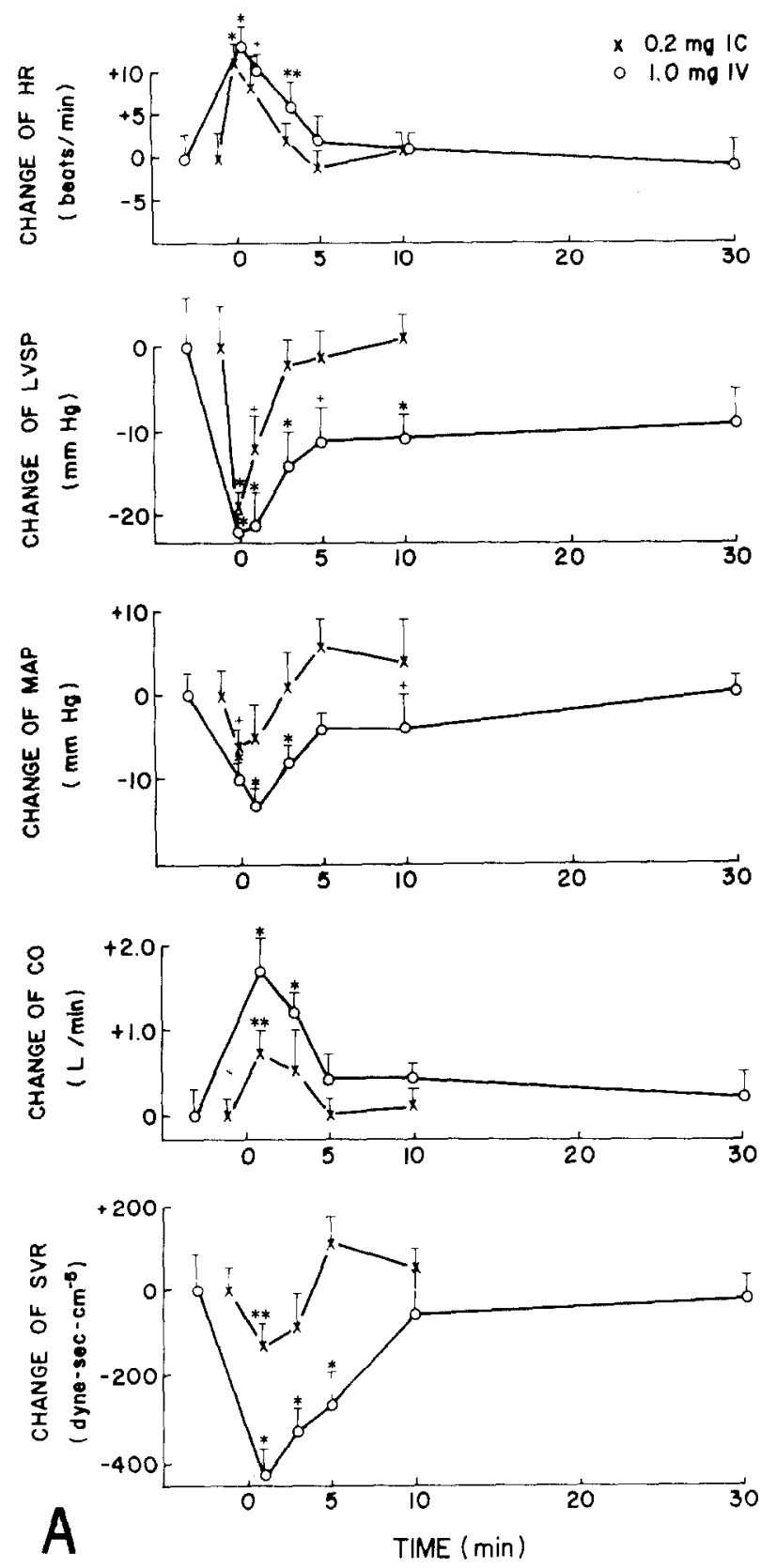

\section{References}

1. Henry PD. Comparative pharmacology of calcium antagonists: nifedipine, verapamil and diltiazem. Am I Gardiol 1980;46:1047-1058.

2. Stone PH, Antman EM, Muller JE, Braunwald E. Calcium channelblocking agents in the treatment of cardiovascular disorders. Part II. Ann Intern Med 1980;93:886-904.

3. Goldberg S, Reichek N, Wilson J, Hirshfeld JW, Muller J, Kaster JA. Nifedipine in the treatment of Prinzmetal's [variant] angina. Am J Cardiol 1979;44: 804-810.

4. Bertrand ME, Lablanche JM, Tilmant PY. Treatment of coronary artery spasm by intracoronary injection of nifedipine and long term evaluation of the effects of nifedipine. In: Pued h P. Krels P, eds. New Therupy for Ischemic Heart Disease. 4th International Adalat Symposium. Amsterdam: Excerpta Medica, 1980:103-109.

5. Hugenholtz PG, Michels HR, Serruys PW, Brower RW. Nifedipine in the treatment of unstable angina, coronary spasm and myocardial ischemia. Am J Cardiol 1981;47:163-173.

6. Moskowitz RM, Piccini PA, Nacarelli GV, Zelis R. Nifedipinc therapy for stable angina pectoris: preliminary results of effects on angina frequency and treadmill exercise response. Am J Cardiol 1979;44:811-816.
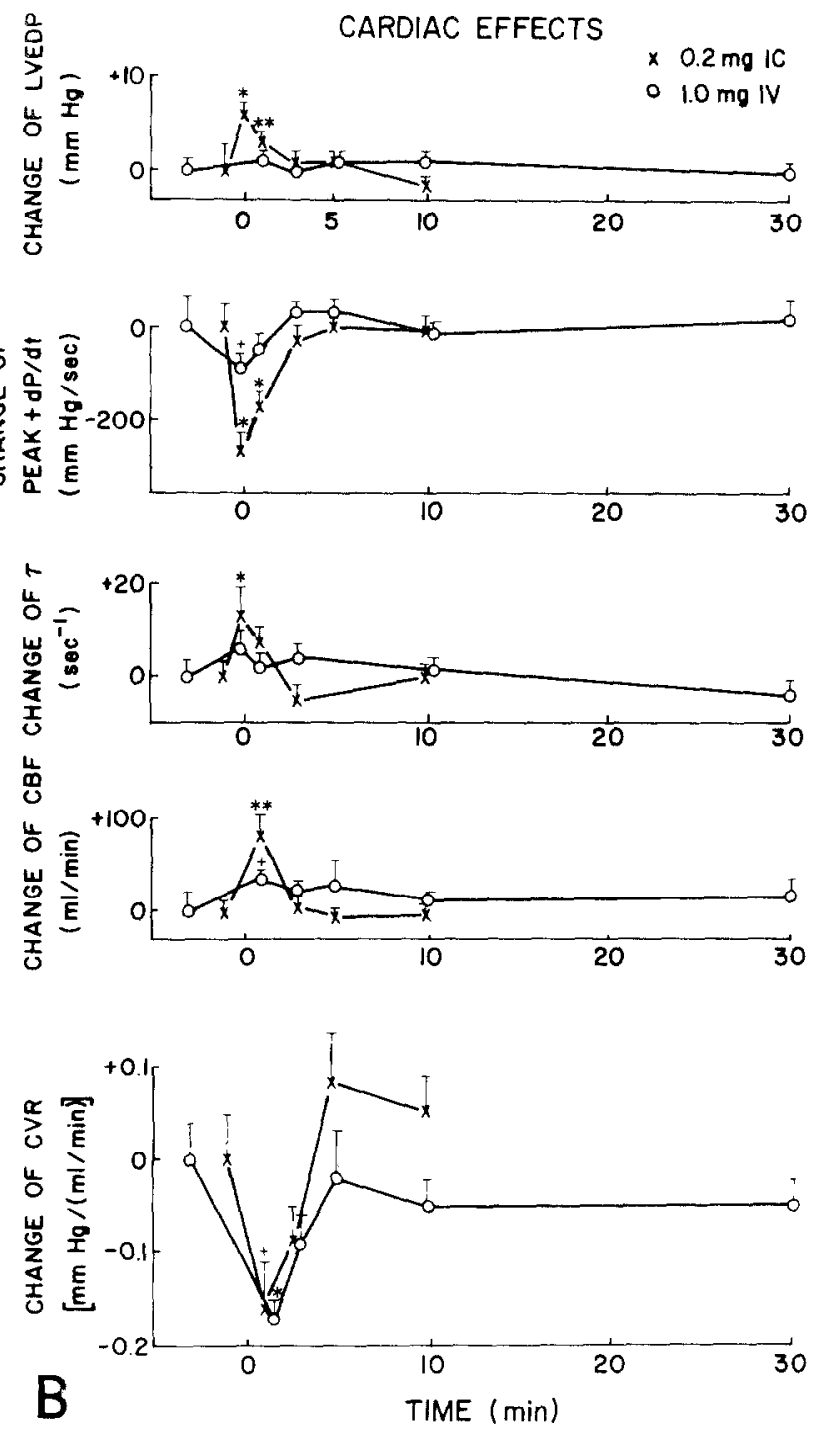

FIGURE 2. Time course of (A) systemic and (B) cardiac effects of $0.2 \mathrm{mg}$ nifedipine infused by the intracoronary and $1.0 \mathrm{mg}$ by the intravenous route. Data are expressed as absolute change from baseline value \pm standard error of the mean. " $p<0.01$; $\mathrm{tp}<0.025$; * $p<0.05$ by paired $t$ test. $\mathbf{H R}=$ heart rate; LVSP = left ventricular systolic pressure; other abbreviations as in Figure 1.

7. Lynch P, Dargie H, Krikler S, Krikler D. Objective assessment of antianginal treatment: $a$ double blind comparison of propranolol, nifedipine and their combination. Br Med / 1980;281:184-187.

8. Lorell BH, Turi Z, Grossman W. Modification of left ventricular response to pacing tachycardia by nifedipine in patients with coronary artery disease. Am I Med 1981;71:667-675.

9. Engel HJ, Lichtlen PR. Beneficial enhancement of coronary blood flow by nifedipine. Am I Med 1981:71:658-666.

10. Emanuelsson H, Holmberg 5. Mechanisms of angina relief after nifedipine: a hemodyrumic and myocardial metabolic study. Circulation 1983;68: 124-130.

11. Specchia G, De Servi S, Falcone C, Angoli L, Gavazzi A, Bramucci E, Mussini A, Ferrario M, Salerno J, Monlenartini C. Effects of nifedipine on coronary hemodynamic findings during exercise in patients with stable exertional angina. Circulation 1983;68:1035-1043.

12. Kaltenbach M, Schultz W, Kober G. Effects of nifedipine after inlruvenous and intracoronary administration. Am J Cardiol 1979;44:832-838. 13. Schanzenbacher P, Lieban G, Deeg P, Lochsiek K. Effect of intravenous and intracoronary nifedipine on coronary blood flow and myocardial oxygen consumption, Am I Cardiol 1983;51:712-717.

14. Verdouw PD, ten Cate F], Hartog JM, Scheffer MG, Stam H. Intracoro- 
nary infusion of small doses of nifedipine lowers regional myocardiol $\mathrm{O}^{2}$. consumption without altering regional myocardial function. Basic Res Curdiol 1982;77:26-33.

15. Serruys PW, Brower RW, ten Katen HJ, Bom AH, Hugenholtz PG. Regional wall motion from radioopaque markers after intravenous und intrucoronary injection of nifedipine. Circulation 1981;63:584-591.

16. Rousseau MF, Veriter C, Detry JMR, Brasseur L, Pouleur H. Impaired early left ventricular relaxation in coronary artery disease: effects of intracoronary nifedipine. Circulation 1980;62:764-772.

17. Weiss JB, Frederiksen JW, Weisfeldt JL. Hemodynamic determinants of the time course of fall in the canine left ventricular pressure. I Clin Invest 1976;58:751-760.

18. Frederiksen JW, Weiss JL, Weisfeldt JL. Time constant of isovolumic pressure fall: determinants of the working left ventricle. Am J Physiol 1978;235:H701-H706.

19. Rooke GA, Feigl EO. Work as a correlate of left ventricular oxygen consumption and the problem of catecholamine oxygen wasting. Circ Hes 1982;50:273-286.

20. Koch G. Beta-receptor and calcium blockade in ischemic heart disease: effects on systemic and pulmonary hemodynamics and on plasma catecholamines at rest and during exercise. 4th International Adalat Symposium. Amsterdam: Excerpta Medica, 1980:131-142.

21. Barnes GE, Horowitz ND, Bishop VS. Reliability of the maximum derivatives of left ventricular pressure and internal diameter as indices of the inotropic state of the depressed myocardium. Cardiovasc Res 1979;13:652666 .
22. Serruys PW, Hooghoudt TEH, Reiber JHC, Slayer C, Brower RW, Hugenholtz PG. Influence of intracoronary nifedipine on left ventricular function, coronary vasomotility, and myocardial oxygen consumption. $\mathrm{Br}$ Heart J 1983;49:427-441.

23. Paulus OJ, Serizawa T, Grussman W. Altered left ventricular diastolic properties during pacing-induced ischemia in dogs with coronary stenoses. Circ Res 1982;50:218-227.

24. Weisfeldt ML, Armstrong P, Scully HE, Sanders CM, Daggett WR. Incomplete relaxation between beats after myocardial hypoxia and ischemia. J Clin Invest 1974;53:1626-1636.

25. McLaurin LP, Rollett EE, Grossman W. Impaired left ventricular relaxation during pacing-induced ischemia. Am I Cardiol 1973;32:751-757.

26. Barry WH, Grooker JZ, Alderman EL, Harrison DC. Changes in diastolic stiffness and tome of the left ventricle during angina pectoris. Cinculation 1974;49:255-263.

27. Bourdillon PD, Lorell BH, Birsky I, Paulus WI, Wynne J, Grossman W. Increased regional myocardial stiffness of the left ventricle during pacinginduced angina in man. Circulation 1983;67:316-323.

28. Marlinger JS, DeWinter MM, Mahler F, Engler R, O'Rourke R. Pharmacological and hemodynamic influences on the rate of isovolumic left ventricular relaxation in the normal conscious dog. I Clin Invest 1977;60:511-521.

29. Morad M, Rolett EL. Relaxing effects of catecholamines on mammalian heart. J Physiol 1972;224:537-558.

30. Lorell BH, Barry WH. Effects of verapamil on contraction and relaxation of cultured chick embryo ventricular cells during calcium overload. JACC $1984 ; 3: 341-348$. 